\title{
Distribution and Fractional Composition of Petroleum Hydrocarbons in Roadside Soils
}

\author{
Larysa Mykhailova, ${ }^{1}$ Thomas Fischer, ${ }^{2}$ and Valentina Iurchenko ${ }^{1}$ \\ ${ }^{1}$ Kharkiv National Automobile and Highway University, 25 Petrovskoho street, 61002 Kharkiv, Ukraine \\ ${ }^{2}$ Brandenburg University of Technology at Cottbus, Central Analytical Laboratory, Konrad-Wachsmann-Allee 6, \\ 03046 Cottbus, Germany
}

Correspondence should be addressed to Thomas Fischer; thomas.fischer@tu-cottbus.de

Received 23 May 2013; Revised 3 September 2013; Accepted 3 September 2013

Academic Editor: Marco Trevisan

Copyright (C) 2013 Larysa Mykhailova et al. This is an open access article distributed under the Creative Commons Attribution License, which permits unrestricted use, distribution, and reproduction in any medium, provided the original work is properly cited.

Total petroleum hydrocarbon (TPH) concentrations and their fractional composition (medium fraction: $\mathrm{n}$-alkane chain-length C15 to C27, heavy fraction: >C27) were determined at distances from 1 to $60 \mathrm{~m}$ from roads and at soil depths from 0.5 to $15 \mathrm{~cm}$. The traffic intensities were up to 25000 vehicles per day. Soil TPH concentrations were highest within $15 \mathrm{~m}$ distance (665 and $3198 \mathrm{mg}$ $\mathrm{kg}^{-1}$ at the windward and leeward sides, resp.), followed by a rapid drop to background values beyond (196 and $115 \mathrm{mg} \mathrm{kg}$ in $60 \mathrm{~m}$ distance at the windward and leeward sides, resp.). The data variability was lowest at distances of $1 \mathrm{~m}$ and highest within tree plantations at distances of $15 \mathrm{~m}$ from the road. The TPH concentrations decreased with depth but were significantly higher than the background at all depths investigated. A principal component analysis revealed a positive relation between the medium-toheavy fraction ratio and soil depth. A fractional differentiation of hydrocarbons with distance from road was not observed. It was concluded that the assessment of the potential of hydrocarbons to translocate, accumulate, or degrade in soil necessitates their subdivision into fractions based on their physicochemical and metabolic properties.

\section{Introduction}

The widespread use of hydrocarbons in fuels causes their predominance among organic atmospheric pollutants, and petroleum products are the major source of anthropogenic hydrocarbon pollutants found in the atmosphere [1-3]. Total petroleum hydrocarbons (TPH) from fossil sources are not readily biodegradable as compared to biomass or soil organic matter, which have been demonstrated to be consumed during hydrocarbon degradation $[4,5]$. Once deposited to the surface, hydrocarbons may persist and bioaccumulate in environmental media [6] and infiltrate into groundwater aquifers via leaching or into surface aquifers by runoff with severe effects on plants $[7,8]$, humans, and animals $[9,10]$. Organic contaminants in roadside soils have been receiving considerable attention as a result of traffic intensity $[1,2$, 11, 12]. Hydrocarbon deposition to ecosystems is of more complex nature, because it is influenced by meteorological and further peripheral conditions, like wind, geomorphology, road construction, buildings, or vegetation, resulting in atmospheric dilution, turbulent exchange, possible wind channeling, and so forth [12].

Apart from studies dealing with individual substances, TPH have been treated in the literature as one class of substances so far. However, as a diverse mix of numerous individual aliphatic hydrocarbons, components of petroleum products also behave individually in the environment. This consideration gives rise to our assumption that an investigation of translocation of TPH through and accumulation of TPH in environmental media must be based on their subdivision at least into fractions of substances with similar physical, chemical, and metabolic properties.

It is the aim of this study to prove the hypothesis that peripheral conditions, in particular vegetation, influence (I) amount and spatial variability of TPH in roadside soils and that the fractional composition of petroleum hydrocarbons 
TABLE 1: General site characteristics.

\begin{tabular}{lccc}
\hline & Traktorostroiteley avenue & Pushkinskaya street & M18 Kharkov-Yalta \\
\hline Traffic density $^{1}$ & 1027 & 774 & 575 \\
Soil texture $^{2}$ & Clayey loam & Loamy clay & Sandy-loamy silt \\
Org. C (\%) & $2.65 \pm 1.87$ & $2.41 \pm 1.39$ & $2.24 \pm 0.97$ \\
$\mathrm{Na}(\%)$ & $0.45 \pm 0.05$ & $0.50 \pm 0.26$ & $0.52 \pm 0.12$ \\
Mg (\%) & $0.43 \pm 0.19$ & $0.40 \pm 0.16$ & $0.43 \pm 0.29$ \\
Al (\%) & $3.42 \pm 1.33$ & $3.20 \pm 1.43$ & $3.47 \pm 2.23$ \\
Si (\%) & $36.96 \pm 3.06$ & $37.62 \pm 2.33$ & $37.10 \pm 4.83$ \\
K (\%) & $1.65 \pm 0.40$ & $1.34 \pm 0.38$ & $2.29 \pm 1.82$ \\
Ca (\%) & $1.91 \pm 0.60$ & $1.39 \pm 0.25$ & $1.32 \pm 0.17$ \\
Mn (\%) & $0.05 \pm 0.02$ & $0.05 \pm 0.01$ & $0.06 \pm 0.01$ \\
Fe (\%) & $1.95 \pm 0.77$ & $2.20 \pm 0.61$ & $1.91 \pm 1.13$ \\
\hline
\end{tabular}

${ }^{1}$ Vehicles per hour, medium values from October 2010, ${ }^{2}$ according to Arbeitsgemeinschaft Boden [13], arithmetic mean values \pm standard deviation.

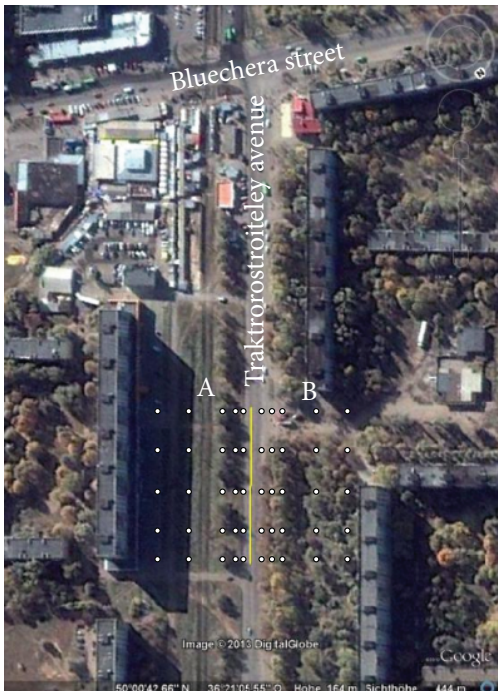

FIGURE 1: Map of the Traktorostroiteley avenue sampling location; A: windward side; B: leeward side; sampling points are marked as white dots, and the yellow line depicts the $100 \mathrm{~m}$ central section of the road. Image source: Google Earth, retrieved 30.08.2013.

changes with (II) distance from the road and (III) with soil depth.

\section{Material and Methods}

Soil samples were collected at distances of $1,6-8,15,40$, and $60 \mathrm{~m}$ and at depths from 0.5 to $15 \mathrm{~cm}$ in October 2010 from the Traktorostroiteley avenue in Kharkov $\left(50^{\circ} 0^{\prime} 41^{\prime \prime} \mathrm{N}\right.$, $\left.36^{\circ} 21^{\prime} 3^{\prime \prime} \mathrm{E}\right)$. Five replicates along a $100 \mathrm{~m}$ section at the windward and the leeward sides of the road, as referred to the long-term main wind direction (sides A and B, resp.), were sampled. A schematic map of the sampling location is given in Figure 1. At distances 3 of $8 \mathrm{~m}$ (windward side A) a single row of birch trees (distance between trees from 6 to $10 \mathrm{~m}$ ) and $4 \mathrm{~m}$ (leeward side B) from the road a double row of maple trees (distance between trees from 4 to $6 \mathrm{~m}$ ) were planted.
In addition, the Pushkinskaya street $(n=4)$ and the M18 highway (pooled samples taken in October 2011, $n=5$ ) were taken into consideration for multivariate statistical analysis. An overview of the sampling sites is given in Table 1 . The $60 \mathrm{~m}$ samples served as background level control. The soil type was Chernozem, developed on Loess at all sampling locations. The long-term mean annual precipitation in Kharkov is $520 \mathrm{~mm}$, and the long-term mean annual temperature is $7.5^{\circ} \mathrm{C}$. Plant litter and biomass are being removed from the surface twice per year in spring and in fall, and an organic soil horizon has not formed on top of the mineral mull horizon.

The samples were air-dried immediately after sampling to prevent microbial degradation of hydrocarbons. Total element concentrations were determined using energydispersive X-ray fluorescence spectroscopy (x-supreme EDXRF analyser, Oxford Instruments, UK). Total soil carbon was determined by dry combustion with $\mathrm{O}_{2}$ at $1050^{\circ} \mathrm{C}$ using a CNS Analyser (Elementar, Germany). Carbonates were determined volumetrically as $\mathrm{CO}_{2}$ after $\mathrm{HCl}$ treatment. Soil organic carbon was determined by subtraction of carbonate-C from total C.

TPH concentrations in soil were determined gravimetrically after triple extraction of $20 \mathrm{~g}$ sieved soil $(<2 \mathrm{~mm})$ with $50 \mathrm{~mL}$ hexane p.a., cleanup over a short aluminum oxide column, and solvent evaporation to constant weight at $40^{\circ} \mathrm{C}$. TPH and fractional composition of petroleum hydrocarbons of selected samples were further determined using GC-MS (Carlo Erba, Fisons) after triple extraction of $2 \mathrm{~g}$ soil with $5 \mathrm{~mL}$ hexane for residue analysis, cleanup over a short fluorosil column, and solvent evaporation under hydrocarbonfree nitrogen at $20^{\circ} \mathrm{C}$ to a sample volume of $10-100 \mu \mathrm{L}$, depending on the results of the gravimetric hydrocarbon determination. Commercial diesel fuel and Hewlett Packard alkane standard Part number 18710-60170 were used for quantification and identification of total hydrocarbons and n-alkanes, respectively. We used an SGE HT8 column at $2 \mathrm{~mL} \mathrm{~min}^{-1}$ helium flow with $1 \mu \mathrm{L}$ split injection at a split ratio of $20: 1$. Injection temperature was $300^{\circ} \mathrm{C}$. The column temperature was $70^{\circ} \mathrm{C}$ during injection and was increased after $1 \mathrm{~min}$ with a heating rate of $30 \mathrm{~K} \mathrm{~min}^{-1}$ and held constant for $20 \mathrm{~min}$ after reaching $320^{\circ} \mathrm{C}$. For detection we used 


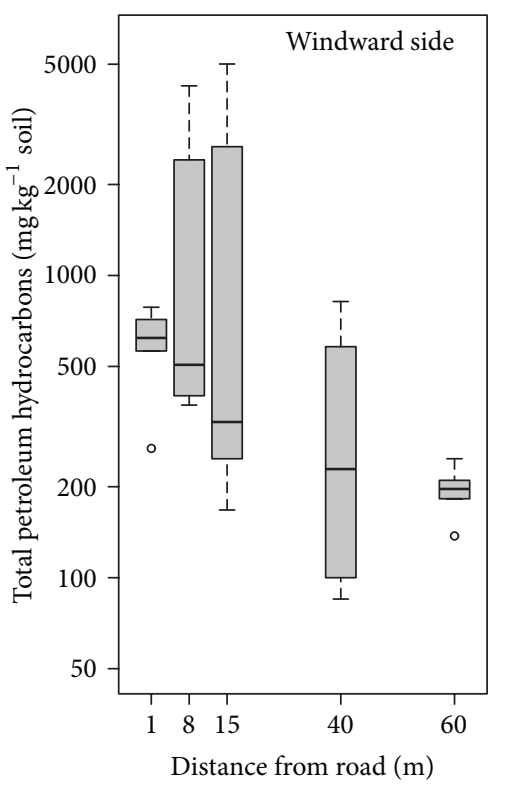

(a)

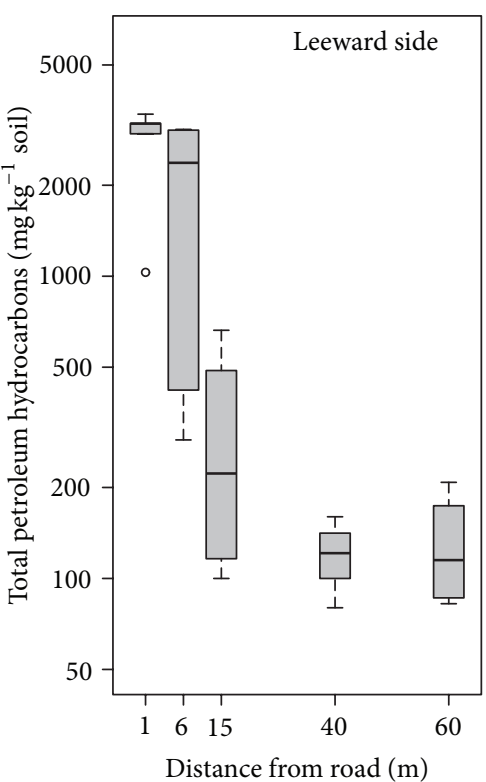

(b)

FIgURE 2: Boxplot of combined GC-MS and gravimetric datasets of TPH concentrations ( $\mathrm{mg} \mathrm{kg}^{-1}$ dry soil) at the windward and leeward sides depending on the distance from road, Traktorostroiteley avenue; bold lines: median values, boxes: upper and lower quartiles, whiskers: data ranges, and circles: outliers.

positive electron impact ionization (EI+) at $70 \mathrm{eV}$ and $\mathrm{MS}$ full scan mode with $\mathrm{m} / \mathrm{z}$ ranging from 50 to 250 . A medium (C15 to C27) and a heavy fraction (>C27) were quantified in the chromatograms using the total ionic current (TIC) after elimination of siloxane signals resulting from column bleeding.

2.1. Statistical Analysis. Box-whisker-plots were used to depict median values (bold lines) and variation (upper and lower quartiles in boxes, data ranges as whiskers, outliers as circles) of TPH concentrations over distance from road. Principal component analysis (PCA) was performed to extract main components explaining the total data variability, where PCA biplots were used to identify correlations between variables. For PCA we used $z$-transformed gravimetric and GC-MS $\mathrm{TPH}$ concentrations, soil organic carbon, $\mathrm{Al}, \mathrm{Fe}$, and $\mathrm{Si}$ concentrations, the distance from road, sampling depth, and the medium-to-heavy fraction ratio. Bivariate regression analysis, Pearson's product moment correlation, and Student's $t$-tests were applied to check for statistical significance. We used the R software suite for all statistical calculations.

\section{Results}

The highest TPH concentrations were observed within a $15 \mathrm{~m}$ strip along the road, followed by a rapid drop to background values beyond. At the leeward side, the TPH concentrations in $1 \mathrm{~m}$ distance from the road amounted to a median value of $3198 \mathrm{mg} \mathrm{kg}^{-1}$ and significantly ( $t$-test, $P<0.01$ ) exceeded the value of $665 \mathrm{mg} \mathrm{kg}^{-1}$ at the windward side by a factor of 4.8. In $60 \mathrm{~m}$ distance from the road, the TPH concentrations amounted to 196 and $115 \mathrm{mg} \mathrm{kg}^{-1}$ at the windward and leeward sides, respectively, which did not differ significantly ( $t$-test, $P=0.14)$. The data variability was lowest at a distance of $1 \mathrm{~m}$ and highest at a distance of $15 \mathrm{~m}$ from the road, where a general trend of decrease could be observed beyond $15 \mathrm{~m}$ (Figure 2).

Within the soil profiles of the contaminated $15 \mathrm{~m}$ strip, the TPH concentrations decreased with depth but were significantly elevated compared to the control at all depths investigated ( $t$-test, $P<0.05$, Figure 3 ). The highest TPH concentrations were observed within the top $5 \mathrm{~cm}$ of the soil profile.

Aliphatic hydrocarbons were the dominating organic contaminant of the soils, and the sum of PAHs ranged from 0.11 to $3.61 \%$ of the concentration of aliphatics. A list of individual compounds determined and of the unresolved complex mixture (UCM [14]) is given in the appendix. The medium-to-heavy fraction ratio amounted to $0.950,0.856$, $1.637,0.972$, and 0.759 for $1,6-8,15,40$, and $60 \mathrm{~m}$ distance from the road, respectively, as well as to $0.972,2.966$, and 2.097 for $0.5,10$, and $15 \mathrm{~cm}$ sampling depth, respectively.

The first and second components of a principal component analysis (PCA) explained $47.2 \%$ and $22.1 \%$ of the total variance, respectively. Subsequent regression analyses revealed a significant positive relation between the gravimetric and the GC-MS TPH concentrations $(r=0.83, P<0.01)$, as well as a significant positive relation between the mediumto-heavy fraction ratio and soil depth $(r=0.70, P<0.05)$. Both gravimetric (Figures 2 and 4 ) and GC-MS (Figure 4) TPH concentrations decreased with distance from the road. The medium-to-heavy fraction ratio did not correlate with the distance from the road $(r=0.10, P=0.84)$. There was 


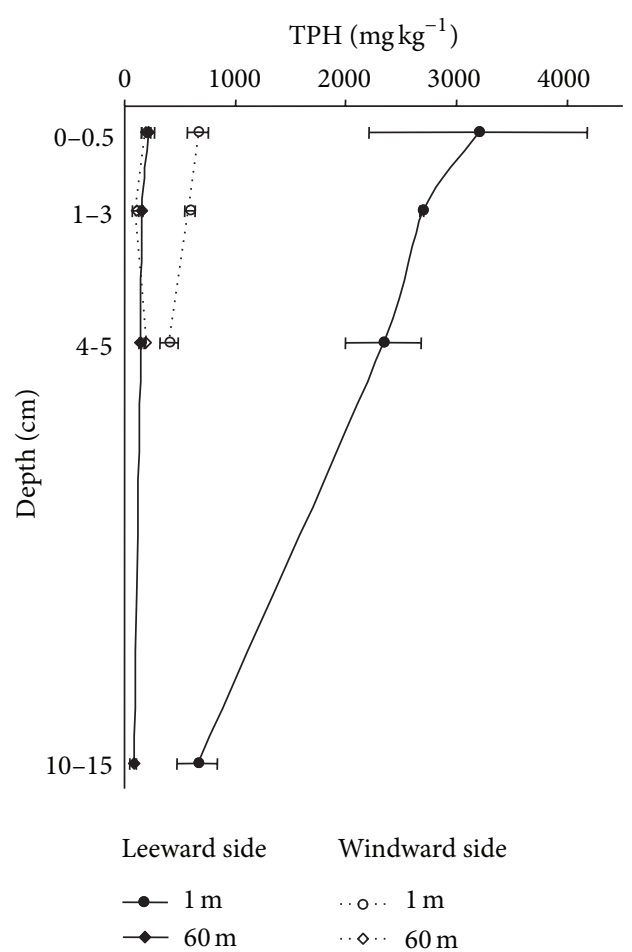

FIGURE 3: Dependence of TPH concentrations (arithmetic mean values \pm standard deviation) from the soil depth at the windward and leeward sides in $1 \mathrm{~m}$ and $60 \mathrm{~m}$ distance from road, Traktorostroiteley avenue.

a significant positive correlation between soil organic carbon, Al $(r=0.79, P<0.01)$, and Fe $(r=0.63, P<0.05)$, but a significant negative correlation between $\mathrm{Si}$, soil organic carbon $(r=-0.78, P<0.01), \mathrm{Al}(r=-0.97, P<0.01)$, and $\mathrm{Fe}(r=-0.91, P<0.01)$. Soil organic carbon did not correlate neither with gravimetric $(r=0.11, P=0.75)$ nor with GCMS TPH concentrations $(r=0.20, P=0.26)$ (Figure 4$)$.

Multiple regression analysis revealed a significant influence of traffic intensity $(F$-test, $P<0.05)$, distance from road ( $F$-test, $P<0.001)$, sampling depth $(F$-test, $P<0.001)$, and period of road exploitation $(F$-test, $P<0.001)$ on total TPH concentrations.

\section{Discussion}

The TPH concentration in soils depends on traffic intensity [ 1 , $2,11,12]$, as well as on meteorological and on further peripheral conditions, like wind, geomorphology, road construction, and buildings, or on vegetation. Hence, TPH amounts along roadside soils reported in the literature vary widely, reaching maximum levels of approximately $1100 \mathrm{mg} \mathrm{kg}^{-1}$ soil in $1 \mathrm{~m}$ distance from a German freeway (50000 vehicles per day, [12]) and up to approximately $19500 \mathrm{mg} \mathrm{kg}^{-1}$ soil in Nigeria [1]. The maximum levels found in this study amounted to $3198 \mathrm{mg} \mathrm{kg}^{-1}$ soil at a traffic intensity of up to 25000 vehicles per day. In particular, for perpendicular approaching wind, markedly higher atmospheric pollutant concentrations at the leeward side and slightly lower concentrations at the

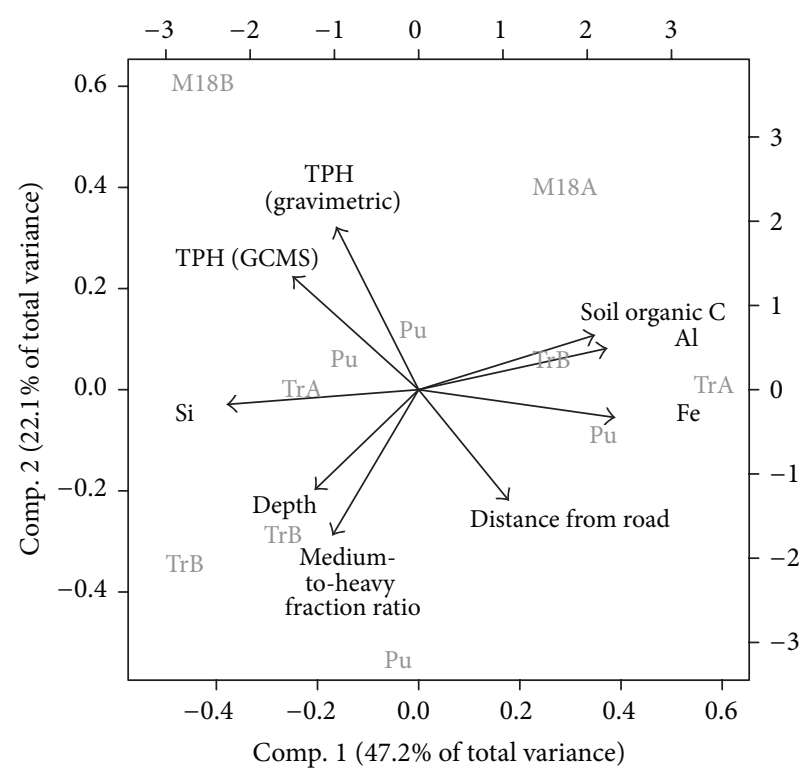

FIGURE 4: Biplot of PCA results after $z$-transformation; TPH: total petroleum hydrocarbons, Pu: Pushkinskaya street, Tr: Traktorostroiteley avenue, and M18: highway; letters A and B denote sampling windward and leeward sides, respectively.

windward side were observed by Gromke and Ruck [15], which may explain the higher soil TPH concentrations at the leeward side here. Unger and Prinz [12] reported that background levels were reached at a distance of $10-25 \mathrm{~m}$ from the road, which could be confirmed by the findings of this study (Figure 2).

With respect to their environmental impact, roads represent a linear source of contamination [12], and consequently low variation at given distance along the road may be expected under homogeneous conditions of TPH translocation, which increases as meteorological and further peripheral conditions vary within that given distance from road. In the present study, high values and low variation of TPH concentrations in $1 \mathrm{~m}$ distance from the road might be due to the influence of splash water carrying high amounts of hydrocarbons from the road surface and due to undisturbed by trees atmospheric hydrocarbon distribution. Surface runoff as major source of hydrocarbon input into soil can be excluded due to the presence of a curb. Ries and Eichhorn [16] reported reduced wind speeds within a vegetated street canyon with a slight increase of pollutant concentrations in the atmosphere. Tree plantings reduced the air exchange between street canyons and the ambience, where in comparison to treeless street canyons higher overall pollutant concentrations and lower flow velocities were measured by Gromke and Ruck [15]. Hence, wind channeling might promote long-distance hydrocarbon transport, whereas buildup of air in the vicinity of trees might cause longer dwell times of hydrocarbon containing air and, thus, may kinetically promote particulate sedimentation or direct adsorption of hydrocarbons to the surface before and reduce hydrocarbon deposition behind the tree rows. Unger and Prinz [12] reported a $35 \%$ increase of the TPH concentration before and 
TABLE 2: Concentrations of individual components (in $\mathrm{mg} \mathrm{kg}^{-1}$ soil) of selected soil samples.

\begin{tabular}{|c|c|c|c|c|c|c|c|c|c|c|c|}
\hline \multirow[b]{3}{*}{ Distance from road (m) } & \multicolumn{5}{|c|}{ Traktorostroiteley avenue } & \multicolumn{2}{|c|}{ M18 } & \multirow{2}{*}{\multicolumn{4}{|c|}{$\begin{array}{c}\text { Pushkinskaya street } \\
\text { Leeward }\end{array}$}} \\
\hline & \multicolumn{3}{|c|}{ Windward } & \multicolumn{2}{|c|}{ Leeward } & \multirow{2}{*}{$\begin{array}{c}\text { Windward } \\
1\end{array}$} & \multirow{2}{*}{$\begin{array}{c}\text { Leeward } \\
1\end{array}$} & & & & \\
\hline & 1 & 6 & 60 & 1 & 1 & & & 1 & 15 & 40 & 100 \\
\hline Soil depth $(\mathrm{cm})$ & 0.5 & 0.5 & 0.5 & 10 & 15 & 0.5 & 0.5 & 0.5 & 0.5 & 0.5 & 0.5 \\
\hline TPH (GC-MS) & 268 & 287 & 197 & 1919 & 1395 & 1273 & 3798 & 1185 & 312 & 453 & 108 \\
\hline Phenanthrene & 0.39 & 0.62 & 0.79 & 4.90 & 1.07 & 0.67 & 13.7 & 2.49 & 1.76 & 1.35 & 0.10 \\
\hline Naphthalene & & & & & & 0.12 & & & & 0.11 & \\
\hline Acenaphthylene & & & & & & & 10.5 & & 0.11 & & \\
\hline Acenaphthene & & & & & & & & & 0.19 & & \\
\hline Fluoranthene & 0.29 & 0.87 & 0.50 & 7.38 & 2.97 & 0.41 & 43.4 & 2.44 & 0.85 & 0.41 & 0.29 \\
\hline Pyrene & 0.14 & 0.59 & 0.26 & 4.07 & 1.62 & 0.19 & 25.9 & 1.43 & 0.51 & 0.18 & 0.16 \\
\hline Benzo(a)anthracene & & & & 2.10 & 0.85 & & 19.8 & 0.66 & 0.19 & & \\
\hline Chrysene & 0.08 & & & 1.99 & 0.67 & & 24.0 & 0.76 & 0.20 & & 0.05 \\
\hline PAH Sum & 0.90 & 2.08 & 1.55 & 20.4 & 7.18 & 1.39 & 137 & 7.77 & 3.81 & 2.04 & 0.59 \\
\hline n-Pentadecane & 0.15 & & & & 0.17 & 0.23 & 0.78 & & 0.25 & 0.33 & \\
\hline n-Hexadecane & 0.38 & 1.04 & & 3.21 & 1.15 & 1.20 & 6.85 & & 1.25 & 1.79 & \\
\hline n-Heptadecane & & 0.60 & & 1.73 & 0.55 & 0.83 & 7.14 & & 1.58 & 1.20 & \\
\hline n-Octadecane & 0.73 & 1.20 & & 4.15 & 1.26 & 2.04 & 20.4 & & 4.02 & 2.18 & \\
\hline n-Nonadecane & 0.36 & & & 2.64 & & 0.96 & 19.4 & & 1.72 & 1.44 & \\
\hline Icosane & 0.39 & 1.23 & & 3.98 & 1.01 & 1.79 & 11.8 & & 2.58 & 1.23 & \\
\hline Heneicosane & 0.62 & 1.09 & & 8.06 & 3.93 & 3.65 & 16.7 & & 7.11 & 1.24 & \\
\hline Docosane & 1.45 & 0.62 & 2.67 & 38.1 & 21.4 & 16.7 & 8.45 & 49.2 & 10.5 & 2.59 & 1.19 \\
\hline Tricosane & 2.53 & & 2.28 & 91.4 & 52.4 & 48.8 & & & 3.76 & 4.08 & 2.28 \\
\hline Tetracosane & 3.41 & 0.16 & 1.25 & 119 & 72.1 & 89.4 & 12.1 & & 2.70 & 5.20 & 3.33 \\
\hline Pentacosane & 4.46 & 0.63 & 0.25 & 111 & 70.0 & 101 & & 15.6 & 4.10 & 6.39 & 3.61 \\
\hline Hexacosane & 4.49 & 0.32 & 0.69 & 89.2 & 60.0 & 95.4 & & 20.1 & 3.12 & 7.14 & 3.29 \\
\hline Heptacosane & 5.57 & 1.23 & 0.18 & 57.5 & 40.6 & 65.2 & & 25.9 & 3.77 & 8.31 & 2.58 \\
\hline Octacosane & 4.32 & 0.66 & 1.04 & 29.7 & 23.3 & 36.9 & & 27.6 & 1.76 & 7.95 & 1.45 \\
\hline Nonacosane & 6.15 & 3.90 & 0.41 & 2.21 & 13.1 & 19.8 & 197 & 29.0 & 3.57 & 10.6 & 1.25 \\
\hline Triacontane & 3.47 & 0.64 & 1.08 & 7.01 & 6.24 & 9.05 & & 24.3 & 0.87 & 7.74 & 0.78 \\
\hline Hentriacontane & 4.65 & 4.85 & 0.15 & 5.71 & 4.30 & 7.28 & 111 & 23.1 & 5.05 & 10.8 & 0.76 \\
\hline Dotriacontane & 1.29 & & 5.65 & 2.23 & 1.87 & 4.02 & 33.0 & 15.8 & & 4.82 & \\
\hline Tritriacontane & 1.43 & & 11.3 & 2.24 & 1.07 & 2.44 & 21.4 & 14.3 & & 4.71 & \\
\hline Tetratriacontane & 2.10 & & 3.20 & 3.70 & 1.54 & 1.03 & & 6.29 & 1.31 & 2.57 & \\
\hline Pentatriacontane & 2.68 & & & & & 0.93 & & 1.47 & 1.39 & 1.33 & \\
\hline $\mathrm{UCM}$ & 216 & 267 & 165 & 1316 & 1012 & 763 & 3194 & 914 & 248 & 357 & 87 \\
\hline$\% \mathrm{UCM}$ & 81 & 93 & 84 & 69 & 73 & 60 & 84 & 77 & 79 & 79 & 80 \\
\hline
\end{tabular}

Empty cells: below detection limit (PAH: $0.05 \mathrm{mg} \mathrm{kg}^{-1}$; alkanes: $0.15 \mathrm{mg} \mathrm{kg}^{-1}$ ); UCM: unresolved complex mixture [14].

a 90\% reduction of the TPH concentration behind a forest belt. While the median TPH concentrations dropped with distance from the road, the presence of trees, hence, increased their spatial variability. Nonsignificant TPH concentrations in $60 \mathrm{~m}$ distance from the road at the windward and leeward sides point to their natural background (Figure 2). It should be noticed here that TPH concentrations at the windward side tended to exceed those of the leeward side in $60 \mathrm{~m}$ distance, which could not be expected in case of their translocation with prevailing winds. The insignificant relation between TPH concentration and traffic intensities found in this study points to the high relevance of meteorological and further peripheral local conditions.
Unger and Prinz [12] reported elevated TPH concentrations compared to the background level in a soil depth of $10 \mathrm{~cm}$. In our study, we observed significantly elevated TPH concentrations down to our maximum sampling depth of $15 \mathrm{~cm}$, indicating vertical translocation of hydrocarbons into the soil profile (Figure 3 ). The positive relation between the medium-to-heavy fraction ratio and soil depth as revealed from PCA (Figure 4) points to enhanced mobility of medium hydrocarbons and to their accelerated translocation into the soil profile, as compared to the heavy fraction. This phenomenon might be explained by decreasing with chainlength hydrocarbon solubility in water and biodegradability, as well as by increasing with chain-length adsorption to 
the soil matrix, resulting in enhanced retention of heavier hydrocarbons along the path of water movement and in their relative accumulation in the upper soil. The enhanced mobility of the medium hydrocarbon fraction further imposes a risk to its movement into deep soil, where accumulation may be promoted by unfavorable conditions for biodegradation. A fractional differentiation of hydrocarbons along their atmospheric distribution path could not be observed within the $60 \mathrm{~m}$ strip of investigation.

Stabilization of soil organic matter by mineral surfaces, in particular by polymeric $\mathrm{Fe}$ and $\mathrm{Al}$ species, has been reported by Mikutta et al. [17]. In our study, soil organic carbon was associated with mineral phases rich in $\mathrm{Fe}$ and $\mathrm{Al}$ but was negatively correlated with mineral phases rich in Si. High concentrations of soil organic carbon, however, were not specifically associated with high TPH concentrations, indicating that the accumulation of petroleum hydrocarbons in soil was most likely controlled by site history and by peripheral conditions.

\section{Conclusions}

It can be concluded from the present results that petroleum hydrocarbons, presenting a mixture of numerous individual substances, behave nonuniformly in soil. To assess their potential to translocate, accumulate, or degrade in soil, it is necessary not only to determine total petroleum hydrocarbon concentrations but also to further subdivide them into fractions based on their physicochemical and metabolic properties.

\section{Appendix}

See Table 2.

\section{Conflict of Interests}

Larysa Mykhailova, Thomas Fischer, and Valentina Iurchenko have no conflict of interests.

\section{Acknowledgments}

The authors are grateful to the Ministry of Education and Science of the Ukraine and to the German Academic Exchange Service (DAAD) for financial support.

\section{References}

[1] A. A. Adeniyi and O. J. Owoade, "Total petroleum hydrocarbons and trace heavy metals in roadside soils along the LagosBadagry expressway, Nigeria," Environmental Monitoring and Assessment, vol. 167, no. 1-4, pp. 625-630, 2010.

[2] J. O. Okonkwo, O. R. Awofolu, S. J. Moja, P. C. B. Forbes, and Z. N. Senwo, "Total petroleum hydrocarbons and trace metals in street dusts from Tshwane Metropolitan Area, South Africa," Journal of Environmental Science and Health A, vol. 41, no. 12, pp. 2789-2798, 2006.

[3] E. S. Manahan, Fundamentals of Environmental Chemistry, Lewis, Chelsea, Mich, USA, 4th edition, 1993.
[4] A. Zyakun, S. Nii-Annang, G. Franke, T. Fischer, F. Buegger, and O. Dilly, "Microbial actvity and13C/12C ratio as evidence of $\mathrm{N}$-hexadecane and $\mathrm{N}$-hexadecanoic acid biodegradation in agricultural and forest soils," Geomicrobiology Journal, vol. 28, no. 7, pp. 632-647, 2011.

[5] O. Dilly, S. Nii-Annang, G. Franke, T. Fischer, F. Buegger, and A. Zyakun, "Resilience of microbial respiration, respiratory quotient and stable isotope characteristics to soil hydrocarbon addition," Soil Biology and Biochemistry, vol. 43, no. 9, pp. 18081811, 2011.

[6] B. J. Alloway, "Land contamination and reclamation," in Understanding Our Environment. An Introduction to Environmental Chemistry and Pollution, R. M. Harrison, Ed., pp. 144-163, Royal Society of Chemistry, Cambridge, UK, 1992.

[7] G. Adam and H. Duncan, "Influence of diesel fuel on seed germination," Environmental Pollution, vol. 120, no. 2, pp. $363-$ $370,2002$.

[8] K. Masakorala, J. Yao, H. Guo et al., "Phytotoxicity of long-term total petroleum hydrocarbon-contaminated soil-a comparative and combined approach," Water, Air \& Soil Pollution, vol. 224, article 1553, 2013.

[9] A. Amadi, S. D. Abbey, and A. Nma, "Chronic effects of oil spill on soil properties and microflora of a rainforest ecosystem in Nigeria," Water, Air, and Soil Pollution, vol. 86, no. 1-4, pp. 1-11, 1996.

[10] P. H. Albers, "Petroleum and individual polycyclic aromatic hydrocarbons," in Handbook of Ecotoxicology, D. T. Haffman, B. A. Rattner, G. A. Burton, and J. Cairns, Eds., pp. 330-335, Lewis, London, UK, 1995.

[11] M. Biasioli and F. Ajmone-Marsan, "Organic and inorganic diffuse contamination in urban soils: the case of Torino (Italy)," Journal of Environmental Monitoring, vol. 9, no. 8, pp. 862-868, 2007.

[12] H.-J. Unger and D. Prinz, Verkehrsbedingte Immissionen in Baden-Württemberg-Schwermetalle und organische Fremdstoffe in straßennahen Böden und Aufwuchs, Ministerium für Umwelt Baden-Württenberg, Luft, Boden, Abfall, Heft, 1992.

[13] A. G. Boden, Bodenkundliche Kartieranleitung, 5. Verbesserte und Erweiterte Auflage, Schweizerbarthsche, Stuttgart, Germany, 2005.

[14] M. A. Gough and S. J. Rowland, "Characterization of unresolved complex mixtures of hydrocarbons in petroleum," Nature, vol. 344, no. 6267, pp. 648-650, 1990.

[15] C. Gromke and B. Ruck, "On the impact of trees on dispersion processes of traffic emissions in street canyons," BoundaryLayer Meteorology, vol. 131, no. 1, pp. 19-34, 2009.

[16] K. Ries and J. Eichhorn, "Simulation of effects of vegetation on the dispersion of pollutants in street canyons," Meteorologische Zeitschrift, vol. 10, no. 4, pp. 229-233, 2001.

[17] R. Mikutta, M. Kleber, M. S. Torn, and R. Jahn, "Stabilization of soil organic matter: association with minerals or chemical recalcitrance?” Biogeochemistry, vol. 77, no. 1, pp. 25-56, 2006. 

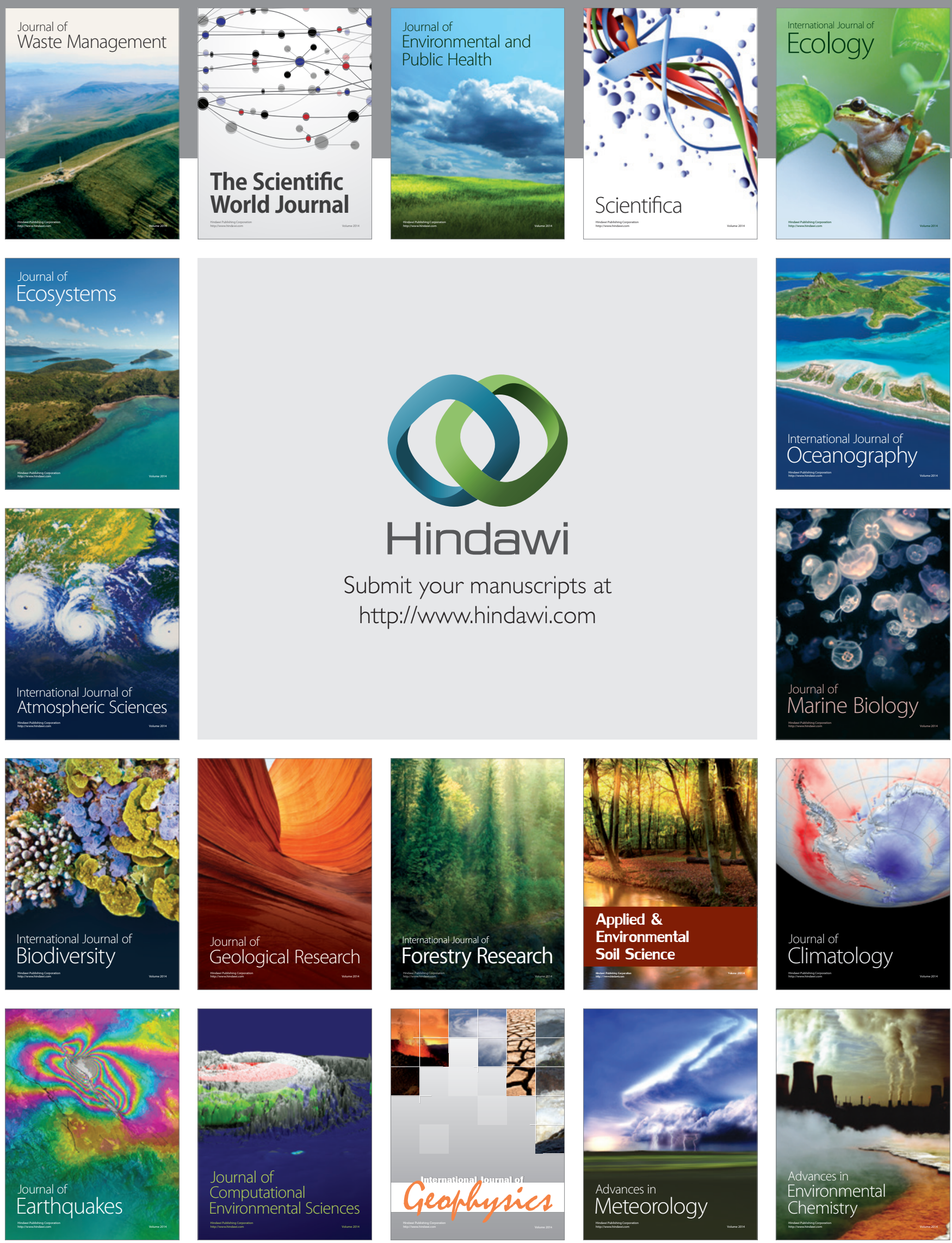